\title{
Status and Economic Rents: Experimental Evidence on the Matthew Effect
}

\author{
David Clingingsmith ${ }^{\mathrm{a}}$ \\ Roman M. Sheremeta ${ }^{a, b, *}$ \\ a Weatherhead School of Management, Case Western Reserve University \\ 11119 Bellflower Road, Cleveland, OH 44106, U.S.A. \\ ${ }^{\mathrm{b}}$ Economic Science Institute, Chapman University \\ One University Drive, Orange, CA 92866, U.S.A.
}

October 25, 2018

\begin{abstract}
Does social status yield economic rents? We conduct an experiment that divides participants into investors and workers. Workers are assigned a social status and then perform a real-effort task. Investors make investments after observing workers' status and past task performance. Workers of higher status receive higher investments when status is derived from ability but not when it is randomly assigned. Higher investment persists even when, conditioning on past performance, status is not predictive of future performance. We refer to the rents thereby earned by high status workers as the Matthew effect. The Matthew effect negatively affects investors' earnings.
\end{abstract}

JEL Classifications: C91, D03

Keywords: status, rent, Matthew effect, investment, experiment

* Corresponding author: Roman M. Sheremeta, E-mail: rshereme@gmail.com and rms246@case.edu We thank Cary Deck, Silke Forbes, Alan Gelder, Mike Price, Eric Schniter, Bart Wilson, Mark Votruba, and seminar participants at Chapman University, the University of Alabama, and the 2018 North American ESA conference for helpful comments. We also thank the Weatherhead School of Management for generous funding of this project. The usual disclaimers apply. 


\section{Introduction}

Why do Ivy League graduates earn more than graduates of other universities? ${ }^{1}$ Economists seeking to answer questions of this type typically proceed as follows. First, they ensure that they have accounted for observable determinants of earnings, such as cognitive ability, age, and race. Then they attempt to apportion the remaining differences in earnings to 1) the treatment effect of an Ivy League education on productivity relative to other schools, 2) selection along unobservable aspects of productivity into Ivy League schools, and 3) residual productivity differences. The attribution of variation in earnings to productivity in this procedure rests heavily on theoretical reasoning because actual worker output is difficult to measure.

In contrast to economists' focus on productivity, sociologists argue that Ivy League graduates earn more because society accords them higher status and that rents accrue to high-status individuals (Sorenson, 1996; Gould, 2002). ${ }^{2}$ Robert Merton (1968) coined the term "Matthew effect” to refer to rents earned by individuals based solely on their status. ${ }^{3}$ Economists tend to discount social-status-derived rent as an explanation of earnings differences because status is not itself a productive input. ${ }^{4}$ In theoretical models of a competitive labor market, the returns to unproductive characteristics such as status are to be driven to zero. Even if productivity is unobservable and employers base hiring decisions on observable characteristics, they will infer employees’ true productivity over time from observable work output (e.g., Holmstrom, 1999). If

\footnotetext{
${ }^{1}$ Studies estimating the returns to college selectivity include Brewer et al. (1999), Dale and Kruger (2002, 2014), Black and Smith (2006), and Hoekstra (2009). See Hoxby (2009) for a general discussion.

${ }^{2}$ Social status is a form of socially-recognized and individually desired esteem or honor that is both positional, in that what matters is how an individual is ranked relative to others, and non-tradable (Heffetz and Frank, 2011).

${ }^{3}$ Merton (1968) argues that eminent scientists tend to get more credit than unknown scientists for an objectively similar piece of scientific work. Azoulay et al. (2014) have found statistical evidence for this tendency in citation patterns of old work for scientists who receive a prestigious award. Merton alludes to a verse in the Gospel of Matthew: "For to everyone who has will more be given, and he will have abundance; but from him who has not, even what he has will be taken away" (Matthew 25:29, Revised Standard Version).

${ }^{4}$ Social status may be correlated with productive characteristics such as skill or serve as a signaling device (Spence, 1973), but except in special cases it is not an input. Such special cases include the
} 
status and productivity are correlated (Spence, 1973), there may be a short-run return to status while it serves this signaling function, but not in the long run.

We present an experiment that tests whether rents from social status persist or are driven to zero in a competitive setting. The experimental setting provides some advantages over observational data in performing this test because it allows output to be observable and enables control over the relationship between status and productivity. Estimating productivity is simpler in our experimental than in the real world, which provides a strong test for the persistence of statusdriven rent. We also decouple worker compensation from employer decisions, which eliminates potential confounds due to moral hazard and social preferences.

In our experiment, participants take on the role of investor or worker. Workers engage in the task of adding up sets of numbers for ten one-minute periods. They are paid a piece rate for each set completed. Investors are assigned a group of three workers and allocate a fixed investment pool among them for each period. Before making their first allocation, investors get a signal of the social status of each the three workers. The investors' return for a period is the sum of the amount invested in each worker multiplied by the number of tasks completed by that worker. Periods are presented to investors in random order. Investors learn and record the actual performance of all three workers at the end of each period for reference.

Three treatments vary the degree to which social status is correlated with productivity in the adding numbers task. Both workers and investors know the basis on which status is assigned in their treatment. In the Random treatment, status labels are assigned randomly. In the Coin treatment, status labels are based on the workers’ relative success at guessing 15 coin flips. There is no correlation either in theory or empirically between adding-numbers performance and status in these two treatments, so investors can maximize their returns by ignoring status investing with 
the worker who has the best past performance. ${ }^{5}$ The difference between them is that status in the Coin treatment derives from actions taken by the workers, which investors may misinterpret as meaningful. The Math treatment assigns status based on relative performance on a math quiz, which is correlated with adding numbers performance both by theoretical reasoning and empirically. In this case, status may be predictive of future performance conditional on past performance.

When investors make their first of nine allocations, the only information they have about workers is their status. In the Math treatment, a rational investor will use status as a proxy for expected performance by correctly inferring that they are correlated. In the Random and Coin treatments, a rational investor will not use status as a proxy for performance and allocate funds equally.

In later periods, the information available to investors includes the record of the past performance of workers in addition to status. A rational investor's decision will combine this information to form the best prediction of performance for each worker. We should expect the conditional importance of status for allocation to fall over time in the Math treatment. If status fails to predict performance conditional on past performance, it should not predict the investor's allocation.

We find that status is uncorrelated with worker performance in the Random and Coin treatments and correlated with performance in the Math treatment. When we control for the mean and standard deviation of past performance and pool all periods, worker performance is uncorrelated with status in all three treatments. This implies a rational investor's allocation should be correlated with status only for the initial periods in the Math treatment.

\footnotetext{
${ }^{5} \mathrm{~A}$ risk averse investor may consider the variance of past returns and allocate a positive amount to all three workers.
} 
In the initial periods of investment, investors allocate more to higher status workers in both the Math and Coin treatments, though not the Random treatment. The correlation between status and investment in the Coin treatment is evidence of the Matthew effect. When we pool all periods, past performance is a strong predictor of investment in all three treatments, though with a larger effect size in the Random treatment. Nevertheless, there is a robust conditional correlation between investors' allocations and status in both the Coin and Math treatments. When we look at the final five periods of investment alone to allow for learning, there remains a conditional correlation between status and investment in the Math treatment.

Investors thus exhibit the Matthew effect when status is derived from workers' actions but not when it is purely arbitrary. When status is unrelated to performance, investors learn to discount it with experience. When status is related to performance, investors allocate more funds to high status workers than their past performance warrants, which is evidence of the Matthew effect. If investments were linked to worker compensation, workers would earn status-based rent. Since we have decoupled worker compensation from investor decisions, we know that the over-allocation cannot be due to investors wanting workers to earn more because of their status. Instead, status biases investor allocations against their own interest in a setting where the correct allocation is relatively easy to infer. As a result, this status bias (the Matthew effect) negatively affects investors' earnings.

We describe the theoretical background, experimental design and procedures of our experiment in Section 2. Our main results are presented in Section 3, along with analyses of how status attracts investments and how history impacts this relationship. We discuss connections to the literature and implications of our results in Section 4. 


\section{Methodology}

\subsection{Theoretical Background}

A number of economic decisions, including employment and investment, share the following structure: A principal makes an allocation of resources or tasks across a set of agents based on expectations about how the agents will perform. The agents' performance generates a return to the principal proportional to the allocation. When forming their expectations of agent performance, principals consider available information about the agents. Relevant information has predictive power about future performance. Our hypothesis is that status is often a factor in such allocations even when it has no predictive power about the performance of an agent, conditional on the other information available. Indeed, principals may have difficulty distinguishing relevant from irrelevant information (Laffont and Martimort, 2002), and the Matthew Effect reflects a specific type of such difficulty, leading to systematic failures to optimize.

In the classic principal-agent setting, payoffs to both parties are affected by the decisions of each. This linkage can give rise to moral hazard, as the agent may adjust performance in the present to influence the future (Holmstrom, 1999). The literature on gift exchange suggests that the allocations made by principals can affect the performance of agents through mechanisms such as reciprocity or other-regarding preferences (Fehr et al., 1993; Charness and Kuhn, 2011). To set aside the analytical complications entailed by such behavioral responses, we consider a simplified setting in which principals cannot influence agents' payoffs. Agents perform a repeated task for a fixed piece rate. Principals earn returns that are the product of their investment allocation to an agent and that agent's task performance. Agents are not informed of the principals' allocations, and principals know this. This setting has characteristics of investment and employment, so we refer to principals as investors and the agents as workers. 
Consider a set of $N$ workers of varying ability who perform a task for $T$ periods. We denote the output of worker $i$ in period $t$ by $y_{i t}$. The workers' payoff in each period is $\pi_{i t}=\rho y_{i t}$, where $\rho$ is a piece rate. The process generating output is $y_{i t}=x_{i}+\varepsilon_{i t}$, which can be decomposed into an worker's unobserved ability $x_{i}$ and a mean-zero i.i.d. unobserved shock $\varepsilon_{i t} \cdot{ }^{6}$ In each period, a single investor has a budget $R$ to allocate among the workers. Let $r_{i t}$ denote the allocation to worker $i$ in period $t$, where $\sum_{i=1}^{N} r_{i t}=R$. The investor earns the payoff $\Pi=\sum_{i=1}^{N} r_{i t} y_{i t}$ from their allocations.

In this setting, the workers wish to produce as much as possible, but their efforts in doing so do not depend on the allocation of the investor. The investor's allocation only affects his or her own payoff. The only information available to the investor to make allocation decisions at time $t$ is the past performance of the workers $\left\{y_{11}, \ldots, y_{N, t-1}\right\}$. Because the shock $\varepsilon_{i t}$ is i.i.d, standard portfolio theory (e.g., Markowitz, 1952) predicts that, for a risk averse investor, the allocation decision in period $t$ should optimally depend only on the sample mean and variance of the performance of each worker through $t-1$. The variance is a factor because a risk averse investor may choose a portfolio with less than the maximum expected return if that portfolio has a lower expected variance. The allocation of a risk-neutral investor would depend only on past mean performance.

Now suppose that before period 1 begins each worker $i$ is assigned a status level $s_{i}$ that is observed by the principal. Status $s_{i}$ could be positively correlated with the worker's ability $x_{i}$, say if it is assigned by some kind of merit, or uncorrelated if assigned randomly. Since in period 1 the

\footnotetext{
${ }^{6}$ Note that here we assume that performance is a function of ability rather than ability and effort. However, this simplification is due to the fact that in our experiment there is no outside option for workers, and so they should exert maximum effort. Consequently, it should be the case that higher ability implies higher output (Laffont and Martimort, 2002).
} 
investor has no information about the worker's prior performance, if $s_{i}$ is correlated with $x_{i}$ the investor may use status to make an allocation decision $r_{i 1}$, so that $s_{i}$ and $r_{i 1}$ will be correlated. However, as the time progresses and the investor observes the performance $y_{i t}$ after each period $t$, the investor forms more accurate expectations about the worker's future performance via the sample mean $\bar{y}_{i t}=\frac{1}{t} \sum_{a=1}^{t} y_{i a}$. As $t$ grows, status will confer less and less information about performance conditional on $\bar{y}_{i t}$, so that as long as the investor makes allocations according to standard portfolio theory $r_{i t}$ and $s_{i}$ will eventually cease to be correlated. This change in the importance of $s_{i}$ is a simple consequence of Bayesian updating after each period.

Sociologists such as Gould (2002) suggest that principals do not treat information about status as suggested by standard portfolio theory. Instead, they assign weight to status information in their decisions even when it is uninformative about expected performance, leading to greater allocation to high status agents and lower allocation to low status agents than expected performance would justify. After Merton (1968), we refer to the overweighting of status in the allocation of resources as the "Matthew effect." In our framework, we would say the investor exhibits the Matthew effect if his/her allocations are correlated with status even when status is not informative about future performance of the worker conditional on other information available, such as past performance. In terms of our framework, the Matthew effect is finding that $E\left(r_{i t} s_{i}\right) \neq$ 0 when $E\left(y_{i t} s_{i} \mid \bar{y}_{i, t-1}\right)=0$. We develop our experiment to test this proposition.

\subsection{Experimental Design and Procedures}

\subsubsection{Overview of the Experiment}

The experiment was conducted in four parts as illustrated in Figure 1. Participants were divided into groups of six. In part 1, groups were assigned to one of three treatments - Random, 
Coin, and Math. Participants then performed activities that we used to assign status categories in part 3. In part 2, three participants in each group were assigned to the role of worker and three to the role of investor. Workers then completed 10 rounds of a piece rate task while investors completed a survey. In part 3, workers were assigned to status categories based on part 1 . Then, having been informed of the status of the three workers with which they were matched, investors allocated a fixed amount of money among the three workers in their group and earned a return based on the worker's performance, which was revealed after the allocations were made. They repeated this for each of the rounds from part 2. This design ensures that the choices made by investors have no influence on the performance or earnings of workers, ruling out those factors as explanations for behavior. In part 4, participants completed an incentivized measure of risk aversion and received their payoffs.

At the beginning of the experiment, participants were told that there would be four independent parts and that the new set of instructions (available in Appendix A) would be given to them at the beginning of each part. The experimenter read the instructions for each part aloud. We implemented the design using a computer interface z-Tree (Fischbacher, 2007). A total of 192 undergraduate students participated in 8 experimental sessions at the Economic Science Institute laboratory at Chapman University. Each session lasting between 70 and 80 minutes had 24 participants in four groups.

\subsubsection{Status Activities}

In part 1, groups were placed in one of three treatments that we label as Random, Coin, and Math. Treatments varied at the session level (i.e., between-subject design). There were 2 sessions of the Random treatment, 3 sessions of the Coin treatment, and 3 sessions of the Math treatment. 
The activities completed in this part were used to assign workers to status categories at the beginning of part 3.

In the Random and Coin treatments, participants were asked to predict the outcomes of a series of 15 coin tosses. Participants were told that the computer would randomly choose whether the outcome of each toss is heads or tails, and that they would earn $\$ 0.40$ for each correct guess. In the Math treatment, participants were asked to solve 10 math questions similar to those asked on the mathematical section of the Graduate Record Examination (Seltzer, 2009). They earned \$0.60 for each correct answer.

The actual earnings for this part of the experiment were computed and communicated at the end of the experiment, and were independent of other parts of the experiment.

\subsubsection{Task Performance by Workers}

In part 2, workers were told that they were in the "business" of adding sets of five twodigit numbers (Niederle and Vesterlund, 2007). The workers' task was divided into 10 periods and in each period they were given one minute to solve as many problems as they could using only paper and pencil. Workers were paid $\$ 0.60$ for each correct answer. The actual earnings for this part of the experiment were determined at the end of the experiment.

Investors were asked to answer a demographic survey while the workers completed their task.

\subsubsection{Status Assignment and Allocations by Investors}

In part 3, the computer assigned status label - gold, silver or bronze - to each worker based on the status activities from part 1 . In the Random treatment, the status label was assigned 
randomly. In the Coin treatment, the computer assigned the labels based on the workers' withingroup ranks in guessing coin flips. The worker who had the most correct coin toss guesses was assigned gold, worker who was second was assigned silver, and worker who was third was assigned bronze. In the Math treatment, the worker who had the most correct answers on math quiz in part 1 was assigned gold, worker who was second was assigned silver, and worker who had the least correct answers on math quiz was assigned bronze.

After status assignment was complete, investors were asked to make 10 investment decisions related to the performance of workers in their group in part 2. For each decision, the investor was asked to allocate $\$ 6$ (i.e., $R=6$ ) among the three workers in their group. The allocations could vary in $\$ 0.10$ increments and had to add up to $\$ 6$. The investor’s earnings for a given decision was calculated as the sum of allocation to a given worker multiplied by the number of problems solved by that worker in the period (i.e., $\sum_{i=1}^{3} r_{i t} y_{i t}$ ). After each investment decision was made, the computer choose one of the 10 periods from part 2 at random (without replacement) and displayed the number of problems solved correctly for each worker in the selected period. ${ }^{7}$ The computer also calculated the investor's earnings based on the investor's allocation to each worker and their corresponding output in that period. Investors were asked to record all relevant information on their personal record sheets, including the performance of workers in the corresponding period. After the experimenter checked that all investors had completed their record sheets, the experiment proceeded. We implemented this procedure to ensure that investors pay attention to previous performance of workers. At the end of the experiment, the computer randomly selected one investment decision for payment.

While investors were making their decisions the workers were given a demographic survey.

\footnotetext{
${ }^{7}$ We randomized the order of periods to eliminate any time trends that may have emerged as workers gained experience with the task.
} 


\subsubsection{Risk Aversion Measures and Payoff}

In part 4, participants made a series of 15 binary choices to measure risk aversion (similar to Holt and Laury, 2002). The choices involved a risk-free amount varying from $\$ 0.50$ to $\$ 7.50$ and a lottery offering a 50\% chance to get $\$ 10$ and a 50\% chance to get nothing (see Appendix A). One of the 15 choices was randomly selected to be paid out at the end of the experiment.

Finally, at the end of the experiment, the computer displayed outcomes from all parts of the experiment and calculated individual earnings. Participants received an average of \$28, including a participation fee of $\$ 7$.

\subsubsection{Remarks on Design Choices}

Some comments concerning our design choices. First, although only workers were assigned a status based on their part 1 performance, we had all participants complete the coin flip or math test in part 1 . We wanted investors to understand the nature of these tasks through experience so that they could judge how much skill was involved. In the Coin treatment, for example, we thought investors would better understand that the number of correct guesses is not a signal of skill, and thus status based on coin flips should be uninformative about performance.

Second, we had workers completing the 10 periods of the adding numbers task before investors had an opportunity to make their 10 investment decisions. This allowed us to eliminate any confounds, such as time trend or learning, that could have occurred in part 2, by randomly selecting one of the 10 periods from part 2 for each of the 10 investment decisions in part $3 .^{8}$

\footnotetext{
${ }^{8}$ Alternatively, we could have used the performance of participants from other sessions and let investors make their decisions based on this "historical" performance of workers (Cason et al., 2010). However, we were concerned that using historical participants would diminish the saliency of status, which is crucial for our study.
} 
Third, we chose to reward all workers using the same piece rate of $\$ 0.60$ before they learned their status. The main reason for this is that we wanted to avoid "the Pygmalion effect" the phenomenon whereby higher expectations lead to an increase in performance (Rosenthal and Jacobson, 1968). ${ }^{9}$ If workers knew that they were of a higher status, potentially they could have tried to work harder in part 2, thus attracting more investments in part 3 . This would have made it more difficult for us to isolate the pure status effect on investments.

Finally, we did not want for the workers' earnings to depend on the investment decisions of investors for two reasons. First, if investors are inequality-averse (Fehr and Schmidt, 1999), they might have tried to minimize inequality by investing more equally among workers. Second, if workers are motivated by reciprocity, they might have responded to greater investment by working harder.

\section{Results}

In this section we present our results. We start by describing the basic patterns of performance and investment in the initial investment periods without conditioning on past performance. We then regression analysis to explore how status is related to performance and investment conditional on past performance and other variables. Finally, we examine potential explanations for our findings.

\footnotetext{
${ }^{9}$ The Pygmalion effect has been observed in principal-agent settings (Gómez-Miñambres, 2012; Corgnet et al., 2015).
} 


\subsection{Basic Findings}

We begin by analyzing the behavior of workers. Table 1 shows the performance of workers in coin-flip guessing or math quiz in part 1 and in adding numbers in part $2 .{ }^{10}$ We break down mean performance by status and by treatment. By design, in the Random treatment, there is no difference in part 1 performance between workers of different status. Also, by design, in the Coin and Math treatments, workers who performed better in part 1 received higher status. Pairwise comparisons using the Wilcoxon signed-rank test fail to reject the null equal performance in the Random treatment and reject the same null in the Coin and Math treatments.

Next, we examine whether the worker's performance in part 1 is predictive of the worker's overall performance across all rounds in part 2. This way we can see whether status (i.e., $s_{i}$ ) is unconditionally informative about an worker's ability (i.e., $x_{i}$ ). We find no significant correlation between part 1 and part 2 performance of workers in the Random treatment (Spearman's $\rho=-0.18$, p-value $=0.41)$ or the Coin treatment (Spearman’s $\rho=0.07$, p-value $=0.67$ ). This is as expected since random assignment and success in guessing coin flips convey no information about ability in adding numbers. However, we find that in the Math treatment, workers who performed better in the math quiz of part 1 also performed better in part 2 (Spearman's $\rho=0.46$, $\mathrm{p}$-value $<0.01$ ). ${ }^{11}$ These findings suggest that while status is unconditionally informative of workers' performance in the Math treatment, it is not informative in the Random and Coin treatments.

Result 1: Status is informative of workers' performance in the Math treatment but not in the Random and Coin treatments.

\footnotetext{
${ }^{10}$ Recall, that in part 1 of the Random and Coin treatments, participants were asked to predict the outcomes of a series of 15 coin tosses. In the Math treatment, participants were asked to solve 10 math questions.

${ }^{11}$ The non-linear relationship between performances in part 1 and part 2 could be due to several reasons. First, adding two-digit numbers (as in part 2) and answering GRE math questions (as in part 1) are two different tasks. Although it is most likely the case that a person who is very bad at adding two-digit numbers is also very bad at answering GRE math questions, a person who is really good at adding numbers may be mediocre GRE test taker. Second, the nonlinearity simply could come from a random noise.
} 
It is not surprising that participants who score higher on the mathematical section of the Graduate Record Examination are also better at adding sets of five two-digit numbers, since both tasks require mathematical computations. Our main question of interest, however, is how investors use this information when making their investment decisions.

Table 2 shows the average allocation decisions of investors by status of workers and by treatment in the first three periods. Recall that in period 1 , the only information investors had about the workers was their status based on the activity completed in part 1. We see that in the Math treatment, investors in period 1 on average allocate $\$ 3.1$ to the gold worker, $\$ 1.8$ to the silver worker, and only $\$ 1.1$ to the bronze worker. All comparisons based on the Wilcoxon signed-rank test produce p-values less than $0.01 .{ }^{12}$ Recall that in the Math treatment status is correlated with performance (Result 1). Therefore, these findings suggest that when the earned status is correlated with performance, higher status workers receive higher investments. Moreover, this effect persists when examining investment differences in period 2 (Wilcoxon signed-rank test, p-values $<0.01$ ) or in period 3 (Wilcoxon signed-rank test, p-values $<0.01$ ).

Result 2: In the Math treatment, where the earned status is correlated with performance, workers of higher status receive higher investments.

The correlation between status and allocation in the Math treatment cannot be attributed only to the Matthew effect, even in later periods, because of the correlation between status and performance. We need to look at the effect of status on allocation conditional on information about the performance of all workers in the group to discover whether investors exhibit the Matthew effect in the Math treatment, which we pursue in Section 3.2.

\footnotetext{
${ }^{12}$ In conducting these non-parametric tests, we first created variables representing the difference between allocations to the gold worker and the silver worker, to the gold worker and the bronze worker, and to the silver worker and the bronze worker. Then we used a Wilcoxon signed-rank test to examine if such differences are significantly different from zero. Note that such non-parametric tests mirror our regression analysis in Sections 3.2.
} 
Next, we examine if status is important even when it is not predictive of the actual performance. Recall that in the Coin treatment status was assigned based on how well the worker could predict a completely random event. As we saw, status earned in this way conveys no information about the actual performance of worker in part 2. Nevertheless, we find that in period 1, investors on average allocate $\$ 2.5$ to the gold worker, $\$ 2.0$ to the silver worker, and only $\$ 1.5$ to the bronze worker. All comparisons based on the Wilcoxon signed-rank test give p-values less than 0.01. These findings suggest that even when the earned status is not correlated with performance, workers of perceived higher status receive higher investments. This effect persists when examining investment differences in period 2 (Wilcoxon signed-rank test, p-values are 0.10, 0.01 and 0.04 ) or in period 3 (Wilcoxon signed-rank test, p-values are $0.33,0.03$ and 0.08 ), but it diminishes in significance.

Result 3: In the Coin treatment, where the earned status is not correlated with performance, workers of higher status receive higher investments.

Result 3 provides some initial evidence in favor of the Matthew effect. Investors allocated more resources to the gold worker than would be justified by the relationship between status and performance. If worker earnings were linked to the allocation of investors as is often the case in a principal-agent setting, the gold worker would earn rent. However, as the investors learn more about the performance of each worker in subsequent periods, the correct way to measure the Matthew effect is to ask whether investors allocate more to gold workers conditional on the history of performance of all workers. We undertake this task in Section 3.2.

It is unlikely that investors allocate more to the workers of higher status to reward workers for their status, since by design higher investments do no benefit workers in any way. One could argue that gold status workers receive higher investments simply because they are labeled as 
"gold." However, this hypothesis is easily dismissed when examining investment decisions in the Random treatment. Recall that in this treatment status was assigned randomly. Looking at Table 2, we see that allocations to workers of different status are very similar in period 1 (Wilcoxon signed-rank test, p-values are 0.84, 0.19 and 0.21), period 2 (Wilcoxon signed-rank test, p-values are $0.80,0.48$ and 0.88 ), and period 3 (Wilcoxon signed-rank test, p-values are $0.31,0.46$ and 0.91). A comparison of the results for Coin and Random suggests that investors interpret status in the Coin treatment to be meaningful other than through a pure label effect.

Result 4: In the Random treatment, where status is assigned randomly, workers of different status receive similar investments.

Together, Results 2, 3 and 4 paint an interesting picture. Result 2 shows that workers of higher status receive higher investments when their status derives from performance and predictive of the actual performance. Result 3 shows that even when status is not predictive of performance, workers of higher status receive economic rents. Finally, Result 4 shows that it is not being labeled as a higher status that matters, but rather the fact that such status is earned (Result 3).

\subsection{Investments and Performance History}

Beginning in the second period, investors know the prior performance of each worker when making their decisions. Portfolio theory suggests that these decisions should depend on the expected mean and variance of the returns provided by each investment. The investors have two types of information to use in estimating their expected returns: past performance and the workers' status. Since status is randomly assigned in both the Random treatment and Coin treatments, in expectation it should be uninformative about performance. Since performance on the math quiz and skill in adding numbers is correlated, status may be informative in the Math treatment, 
particularly when only a few periods of performance data are available, though we would expect it to eventually become uninformative relative to information on past performance.

\subsubsection{Past Performance and Status as Predictors of Current Performance}

We will first investigate how current performance is related to past performance and status by estimating the regression:

$$
p_{j g t}=\beta_{0}+\beta_{1} G O L D_{j g}+\beta_{2} S_{L I V E R} R_{j g}+\beta_{3} m_{j g t}+\beta_{4} s_{j g t}+\beta_{5} \ell_{j g t}+\epsilon_{j g t} .
$$

The variable $p_{j g t}$ represents the performance of worker $j$ of group $g$ in period $t$. The status of worker $j$ is given by the dummies $G O L D_{j g}$ and $S I L V E R_{j g}$. Positive coefficients on these variables indicate differential performance by status.

The specification also includes three variables that capture past performance that we believe will influence investors decisions, which we study in Section 3.2.2. The mean and standard deviation of performance through period $t-1$ are $m_{j g t}$ and $s_{j g t}$ and performance in the last period is $\ell_{j g t}$. Since these variables are only defined for $t>1$ and since the worker's final investment is made with knowledge information through period 9, we focus on periods 2 through 9 in the analysis. Period 10 performance affects payoffs only, not subsequent decisions, because period 10 is the final period. We include these variables here because regressions including them tell us whether status matters for current performance conditional on information about past performance.

We estimate equation (1) separately for each of the three treatments. Results are shown in Table 3. The dependent variable is the level of performance. First, we show a regression of performance on the status dummies alone in columns 1 through 3 to investigate whether status is informative about performance in the absence of other information. The results show that status is 
informative in the Math treatment but not in the Random or Coin treatments. We would expect this to be the case as both performance in adding numbers and on the math quiz are related to mathematical ability. When we add information about performance in prior periods to the regression in columns 4 through 6, however, the status variables are no longer large in magnitude nor statistically significant for any of the treatments. By contrast, the mean of prior performance is a strong and statistically significant positive predictor of current performance while last period's performance is negatively correlated with current performance.

Result 5: Status is correlated with performance in the Math but not in the Coin or Random treatments. Status is uncorrelated with performance conditional on past performance both overall and in the final five periods.

This result shows that status provides no information overall conditional on past performance. A rational investor allocating his or her funds across the three workers should rely on the past means and standard deviations of performance in making their decision and not on the status information. In the next section, we will examine to what extent investors follow this implication.

\subsubsection{Past Performance and Status and Investor's Allocations}

In this section, we study how past performance and status influence investors allocation decisions. We denote the allocation of investors to the gold, silver, and bronze workers in each period by $y_{i g t}^{k}$, where $k=\{G, S, B\}$. How much an investor allocates to any worker depends on how well that worker has performed relative to the other workers. We use a seemingly unrelated regression (Zellner, 1962) to analyze how the investment in each worker depends on a constant, 
the mean performance, standard deviation of performance, and last instance of past performance for all three types of workers $m_{k g t}, s_{k g t}$, and $\ell_{k g t}$.

$$
\begin{aligned}
& y_{i g t}^{G}=\propto_{0}^{G}+\sum_{k=G, S, B} \alpha_{1 k}^{G} m_{k g t}+\sum_{k=G, S, B} \alpha_{2 k}^{G} S_{k g t}+\sum_{k=G, S, B} \alpha_{3 k}^{G} \ell_{k g t}+\alpha_{4}^{G} t+\varepsilon_{i g t}^{G}, \\
& y_{i g t}^{S}=\propto_{0}^{S}+\sum_{k=G, S, B} \alpha_{1 k}^{S} m_{k g t}+\sum_{k=G, S, B} \alpha_{2 k}^{S} S_{k g t}+\sum_{k=G, S, B} \alpha_{3 k}^{S} \ell_{k g t}+\alpha_{4}^{S} t+\varepsilon_{i g t}^{S}, \\
& y_{i g t}^{B}=\propto_{0}^{B}+\sum_{k=G, S, B} \alpha_{1 k}^{B} m_{k g t}+\sum_{k=G, S, B} \alpha_{2 k}^{B} S_{k g t}+\sum_{k=G, S, B} \alpha_{3 k}^{B} \ell_{k g t}+\alpha_{4}^{B} t+\varepsilon_{i g t}^{B} .
\end{aligned}
$$

We add performance in the last period to the mean and standard deviation because the learning literature suggests people tend to weight more recent observations more heavily than those that happened earlier (Erev and Haruvy, 2015). We explore additional aspects of past performance, such as which worker was best, as robustness checks. We also note that estimation of this system using linear regression may be problematic if investors frequently choose the boundary values of 0 or 6 . In practice this happens in only $16 \%$ of decisions. This means that investor portfolios are generally diversified.

In each period, each investor has six dollars to allocate among the three workers. This implies the following equation must be satisfied for each investor and period:

$$
y_{i g t}^{G}+y_{i g t}^{S}+y_{i g t}^{B}=6 .
$$

For equation (5) to always hold, the following must be true:

$$
\begin{aligned}
& \propto_{0}^{G}+\propto_{0}^{S}+\propto_{0}^{B}=6, \\
& \varepsilon_{i g t}^{G}+\varepsilon_{i g t}^{S}+\varepsilon_{i g t}^{B}=0, \\
& \sum_{k=G, S, B}\left(\alpha_{1 k}^{j}+\alpha_{2 k}^{j}+\alpha_{3 k}^{j}\right)+\alpha_{4}^{j}=0 \text { for } j \in\{G, S, B\} .
\end{aligned}
$$


The restriction on the error terms $\varepsilon_{i g t}^{G}+\varepsilon_{i g t}^{S}+\varepsilon_{i g t}^{B}=0$ implies that the variance-covariance matrix of the system described by equations (2) to (4) has rank 2 and is thus singular. ${ }^{13}$ We can overcome this problem by dropping one equation from the estimation. We will drop equation (4). In estimating the remaining two equations, we must also account for the coefficient constraints in equation (8). If we rewrite the constraints for equations (2) and (3) in terms of $\alpha_{4}^{j}$, substitute, and then transform the independent variables using $\tilde{x}_{k g t}=x_{k g t}-t$, we get a two-equation system that can be consistently estimated:

$$
\begin{aligned}
& y_{i g t}^{G}=\propto_{0}^{G}+\sum_{k=G, S, B} \alpha_{1 k}^{G} \tilde{m}_{k g t}+\sum_{k=G, S, B} \alpha_{2 k}^{G} \tilde{s}_{k g t}+\sum_{k=G, S, B} \alpha_{3 k}^{G} \tilde{\ell}_{k g t}+\varepsilon_{i g t}^{G}, \\
& y_{i g t}^{S}=\propto_{0}^{S}+\sum_{k=G, S, B} \alpha_{1 k}^{S} \tilde{m}_{k g t}+\sum_{k=G, S, B} \alpha_{2 k}^{S} \tilde{s}_{k g t}+\sum_{k=G, S, B} \alpha_{3 k}^{S} \tilde{\ell}_{k g t}+\varepsilon_{i g t}^{S} .
\end{aligned}
$$

We can use the coefficients from this estimation and equation (6) to produce an estimate of $\alpha_{0}^{B}$. The null hypothesis that status does not influence allocation is $H_{0}: \propto_{0}^{G}=\propto_{0}^{S}=\alpha_{0}^{B}=2$.

We present the results from estimating the system described by equations (2') and (3') for each of the three treatments in Table 4. The history variables are undefined for the first period so we exclude it from the analysis. We compute standard errors by bootstrap and resample at the investor level.

The estimations in Panel A include all investment choices made in periods 2 through 10, where investors had information on the prior performance of workers. Results for the Random treatment are shown in columns 1 and 2. We see that investment with a given worker depends positively on the past mean and last performance of that worker and negatively on the past mean and last performance of the other. The constant terms are 2.16 for gold, 1.84 for silver, and 2.00

\footnotetext{
${ }^{13}$ See Wooldridge (2001), p. 168.
} 
for bronze. We fail to reject the null hypothesis that they are equal, and thus that status does not influence allocations, with p-value $=0.68$. Status has no effect in the Random treatment.

The Coin treatment shows a similar directional pattern of dependence of investment on the past performance of workers (Panel A, columns 3 and 4). The constant terms are 2.98 for gold, 1.64 for silver, and 1.38 for bronze. We reject the null of equal constants with p-value $<0.01$. Investors thus place more funds with gold and less with silver and bronze than is warranted by past performance. Status has a sizeable and significant effect in the Coin treatment. Recall that the only difference between Coin and Random is that that the mechanism by which status is assigned in the Coin treatment involved making predictions, which can be mistaken for skill or taken to be a sign that someone is "lucky." Also recall that in the Coin treatment, status has no predictive power about actual performance, either unconditionally or conditional on the observable data that investors have.

The overall pattern in the Math treatment is similar to the Coin treatment (Panel A, columns 5 and 6). The constant terms are 3.15 for gold, 1.49 for silver, and 1.36 for bronze. The difference between them is statistically significant with p-value $<0.01$. We saw in Table 3 that in the Math treatment status is a good unconditional predictor of future performance but is uncorrelated with future performance conditional on information about past performance.

Investors may be sensitive not only to the mean, standard deviation, and most recent performance of the workers but also to which one has performed best. This would be particularly true for risk neutral investors, who would not tend to diversify. Appendix Table B1 shows estimation results including dummy variables for which worker had the best performance both overall and in the most recent period. The results are consistent with Table 4, Panel A. 
Investors are in groups of three that are exposed to the same set of workers and thus all have information in common. Appendix Table B1 replicates the analysis in Table 4, Panel A with standard errors clustered at the group level. With the larger standard errors we continue to reject the null of no status effect in the Math treatment but fail to reject it in the Coin treatment.

In pooling the data on periods 2 through 10, we are discounting the possibility that investors may require several periods of experience to be able to form good predictions of future performance. We therefore repeat the analysis of investment decisions for the final five periods. In these periods, investors have seen at least four realizations of worker performance. Estimates of the constant terms and test of the null hypothesis on this subset of periods is shown in Table 4, Panel B. The results show that the effect of status has faded for the Coin treatment but remained robust for the Math treatment. This suggests that investors learn that status is not a conditional predictor of performance in the former case but not in the latter.

Result 6: Investors initially exhibit the Matthew effect in the Coin and Math treatment by allocating investment based on status as well as on past performance, with the effect attenuating over time in the Coin treatment but not in the Math treatment.

It also could be the case that investors in the Math treatment need not only experience, but also sufficient difference between workers (i.e., stronger signal) in order to correctly condition their investments. To check for this, we calculated the mean absolute deviation (MAD) from the mean in performance on the math quiz and then estimated the model on those investors for whom the workers had above or equal to median MAD in math quiz score (see the column 4 in Table 4, Panel B). We might expect that it would be easier for investors to learn about such workers, thus diminishing the Matthew effect. While the coefficients are not very different in the high MAD group, we fail to reject the null that they are equal (p-value=0.24). 


\subsection{Determinants of Investment}

In this section we investigate whether the effects of status on investment differ with the characteristics of the investors. The characteristics we consider include demographic characteristics, risk preferences, and trust.

We found evidence for status effects on investment by estimating equations (2’) and (3’) and comparing the comparing the constant terms. An alternative form of the null hypothesis we tested is $H_{0}: \alpha_{0}^{G}-\alpha_{0}^{S}=0$. If we add dummy variables for the mediating characteristics of interest to equations (2') and (3'), the estimated coefficients within each equation will tell us whether the intercept for that group tends to be conditionally higher or lower than the estimated constant. Taking the difference across equations in the estimated coefficients for each variable provides us with a measure of whether status is more or less important for the investment decisions of that subgroup.

We estimate such a model and provide a table of these cross-equation differences for each mediator in Table 5. In general, the effects of status are not mediated by the characteristics. Most of the coefficients are small and not statistically different from zero. The only exception is in the Math treatment, where those who report being competitive show a larger tendency to invest in gold (column 3).

\subsection{Investments and Earnings}

The final question we ask is how costly is it for investors to exhibit the Matthew effect. Table 6 regresses mean period earning on the treatments. The estimation results in column 1 indicates that investors in the Math treatment earn $\$ 1.74$ less while those in the Coin earn about as much as the Random treatment. In column 2 , we add an interaction with period $\geq 6$. The significant 
interaction coefficient shows that average earnings increase in all treatments, but earnings do not catch-up for the Math treatment. The difference between Math and Coin in the later periods is statically significant.

Columns 3 and 4 use an alternative dependent variable in which we compute the best possible allocation for each period (all six dollars allocated to the highest scorer) and then compute actual earnings as a fraction of this maximum. The estimation results show the same pattern of earnings in the three treatments.

Together, these results show that in the Math treatment, in which the Mathew effect is the strongest, investors receive the lowest earnings.

Result 7: Investors receive the lowest earnings in the Math treatment, indicating that the Matthew effect has a significant negative effect on earnings.

\section{Discussion}

Our experiment sheds light on a mechanism through which social status extracts economic rents. When status is simply a randomly assigned label in the Random treatment, investors ignore it making their allocations in favor of information on the past performance of workers. Here status earns no rent. In contrast, when status is correlated with adding-numbers performance in the Math treatment, investors suffer from the Matthew effect, favoring those of high status even though status does not predict future performance conditional on the information investors possess about past performance. This contrast in behavior suggests that information about status, which is useful in making allocations in the Math treatment in the absence of any other information, impedes investors' learning from past performance as information about it becomes available. This status bias negatively affects investors' earnings. When status is uncorrelated with adding-numbers 
performance but correlated with guessing coin flips in the Coin treatment, investors initially suffer the Matthew effect but learn to discount status over time.

Our findings contrast with the "accountability principle" (Konow, 2000, 2003), which states that remuneration should be based on the relevant variables that an individual can influence (i.e., performance) but not those that he cannot influence (i.e., status). Nevertheless, our findings are consistent with the literature on retrospective voting that finds voters reward/punish politicians based on outcomes over which politicians have no control (Healy et al., 2010; Gasper and Reeves, 2011), as well as the psychology literature on outcome bias (Baron and Hershey, 1988; Marshall and Mowen, 1993). ${ }^{14}$ While our study cannot determine precisely why investors over-rely on status information in making their allocation, a plausible explanation is that status provides an easy to use heuristic that investors substitute for the more difficult task of combining status with past performance (see Kahneman, 2011, chapter 9). However, as investors become more experienced and the status signal becomes more informative, the status bias diminishes in magnitude.

Our study contributes to several areas of research. First, our study contributes to the literature on "the Matthew effect” (Merton, 1968; Azoulay et al., 2014). According to the Matthew effect, people of higher status are rewarded more than people of lower status for an objectively similar work. In this way, our paper is related to Gould (2002) who suggested the Matthew effect as a mechanism by which rents associated with high status could emerge in a competitive setting. Another way of viewing the Matthew effect is that people overweight past experience in assessing the present. In this way, our paper is related to Malmendier and Nagel $(2011,2016)$ who show that experiences of inflation during one's lifetime significantly influences expectations about future inflation and risk-taking. Consistent with both of these strands of literature, we find that workers

${ }^{14}$ There are also recent studies showing that participants often condition their giving and reciprocity on both performance and luck of others (Erkal et al., 2011; Rubin and Sheremeta, 2016; Rey-Biel et al., 2018). 
of higher status receive higher investments (extract economic rents) than workers of lower status and this is true even when status is not predictive of the future performance. ${ }^{15}$

Second, our study is related to the literature on discrimination (Becker, 1957; Phelps, 1972; Arrow, 1973) and stereotypes (Schneider, 2004; Bordalo et al., 2016). For example, Reuben et al. (2014) use a laboratory experiment to show that men are more likely to be hired (invested in) than women even when both genders perform equally well. ${ }^{16}$ Similarly, our findings show that higher status attracts more investment even when such status is not predictive of the actual performance. Combining the results from Reuben et al. and our study, it could be argued that one reason for gender discrimination is that men are assigned higher status (Ridgeway and Bourg, 2004) which is not predictive of the actual performance but yet it extracts economic rents. ${ }^{17}$

Third, our study contributes to the literature on dynamic managerial incentives (Holmström, 1999). The objective of a manager is to infer the productivity of an agent from a series of realizations of output. This could be a difficult task given that the agent may want to distort their productivity in earlier periods in order to elicit higher wage in later periods (Freixas et al., 1985; Charness et al., 2011). The results of our study show that the task of empirically evaluating the agent's productivity may be further complicated by status considerations. Note that the task we gave participants is easier than that faced by most managers in evaluating the ability

\footnotetext{
${ }^{15}$ The finding that higher status leads to higher economic rents is also consistent with the findings of Ball et al. (2001). In their experiment, subjects were assigned either to a higher-status or lower-status side of the market based on a trivia quiz. Similarly to our finding, they found that status leads to higher economic rents (i.e., better prices for the higherstatus side of the market). However, unlike our study, Ball et al.'s design did not allow them to test for the Matthew effect. Moreover, their design involved subjects of higher status earning economic rents themselves; therefore, it is not clear how much of this result is due to status and how much of it is due to "the Pygmalion effect" (see Section 2.2.6 for a discussion on the Pygmalion effect).

${ }^{16}$ This discrimination is hard to eliminate even after applying different interventions designed to overcome gender bias in hiring (Price, 2012; Baldiga and Coffman, 2016; Bohnet et al., 2016).

${ }^{17}$ Similar argument could be made to explain the "beauty premium" of Mobius and Rosenblat (2006). Specifically, Mobius and Rosenblat find that physically attractive people receive a beauty premium even when beauty is not predictive of performance. It could be argued that one reason for such premium is that more beautiful people are perceived as having higher status.
} 
of their employees because individual output was observable. This suggests our study would be biased toward finding a smaller status effect than would be obtained in the labor market. While we do not provide direct evidence of labor market rents accruing to status, this inference is made more plausible by features of the labor market that provide evidence against marginal productivity as the sole determinant of wages, particularly the existence of industry- and establishment-level rents for workers (Dickens and Katz, 1986; Kreuger and Summers, 1988; Card et al., 2013) and the "recursive, self-fulfilling process" (Thaler, 2016) by which executive pay is determined (see Bebchuk and Fried, 2004). Manning (2011) argues that search frictions can account for rents in the labor market. The mechanism we study is separate from but not incompatible with the existence of search frictions.

Finally, our study contributes to the finance literature on investment portfolio composition (Markowitz, 1952). The standard prediction is that the investment decision should depend on the sample mean and variance of the asset. However, recent experimental studies have questioned this proposition by showing that people "believe” in luck (Bou et al., 2016; Suetens et al., 2016) and that investors are willing to pay for random information that has no predictive power (Powdthavee and Riyanto, 2015). Similarly, we find that participants designated as investors in our experiment make their investments based on not only the sample mean and variance of the worker's previous performance, but also on the worker's status, even when such status has no predictive power. 


\section{References}

Arrow, K.J. (1973). The Theory of Discrimination. In Discrimination in Labor Markets, ed. by O. Ashenfelter, and A. Rees. Princeton University Press.

Autor, D.H. (2014). Skills, education, and the rise of earnings inequality among the 'other 99 percent.' Science, 344, 843-51.

Azoulay, P., Stuart, T., \& Wang, Y. (2014). Matthew: Effect or Fable? Management Science, 60, 92-109.

Baldiga, N.R., \& Coffman, K.B. (2016). Laboratory evidence on the effects of sponsorship on the competitive preferences of men and women. Management Science, 64, 888-901.

Ball, S., Eckel, C., Grossman, P.J., \& Zame, W. (2001). Status in markets. Quarterly Journal of Economics, 116, 161-188.

Baron, J., \& Hershey, J.C. (1988). Outcome bias in decision evaluation. Journal of Personality and Social Psychology, 54, 569-579.

Bebchuk, L., \& Fried, J. (2004). Pay without Performance: The Unfulfilled Promise of Executive Compensation. Cambridge, MA: Harvard University Press.

Becker, G. (1957). The Economics of Discrimination. University of Chicago Press.

Bivens, J., \& Mishel, L. (2013). The pay of corporate executives and financial professionals as evidence of rents in top 1 percent incomes. Journal of Economic Perspectives, 27, 57-77.

Black, D.A., \& Smith, J.A. (2006). Estimating the returns to college quality with multiple proxies for quality. Journal of Labor Economics, 24, 701-728.

Bohnet, I., Bazerman, M.H., \& Van Geen, A. (2016). When performance trumps gender bias: Joint versus separate evaluation. Management Science, 62, 1225-1234.

Bordalo, P., Coffman, K., Gennaioli, N., Shleifer, A. (2016). Stereotypes. Quarterly Journal of Economics, 131, 1753-1794.

Bou, S., Brandts, J., Cayón, M., Guillén, P. (2016). The price of luck: Paying for the hot hand of others. Journal of the Economic Science Association, 2, 60-72.

Brewer, D., Eide, E., \& Ehrenberg, R. (1999). Does it pay to attend an elite private college? Crosscohort evidence on the effects of college type on earnings. Journal of Human Resources, 34, 104-23.

Card, D., Heining, J., \& Kline, P. (2013). Workplace heterogeneity and the rise of West German wage inequality. Quarterly Journal of Economics, 128, 967-1015.

Cason, T.N., Masters, W.A., \& Sheremeta, R.M. (2010). Entry into winner-take-all and proportional-prize contests: An experimental study. Journal of Public Economics, 94, 604611.

Charness, G., \& Kuhn, P. (2011). Lab labor: What can labor economists learn from the lab? In O. Ashenfelter \& D. Card (Eds.), Handbook of Labor Economics (pp. 229-331). Amsterdam: Elsevier. 
Charness, G., Kuhn, P., \& Villeval, M.C. (2011). Competition and the ratchet effect. Journal of Labor Economics, 29, 513-547.

Coffman, K.B. (2014). Evidence on self-stereotyping and the contribution of ideas. Quarterly Journal of Economics, 129, 1625-1660.

Corgnet, B., Gómez-Miñambres, J., \& Hernán-Gonzalez, R. (2015). Goal setting and monetary incentives: When large stakes are not enough. Management Science, 61, 2926-2944.

Dale, S.B., \& Krueger, A.B. (2002). Estimating the payoff to attending a more selective college: An application of selection on observables and unobservables. Quarterly Journal of Economics, 117, 1491-1527.

Dale, S.B., \& Krueger, A.B. (2014). Estimating the effects of college characteristics over the career using administrative earnings data. Journal of Human Resources, 49, 323-358.

Dickens, W.T., \& Katz, L.F. (1986). Inter-industry wage differences and industry characteristics. Working Paper.

Erev, I., \& Haruvy, E. (2015). Learning and the economics of small decisions. In Kagel, J.H. and Roth, A.E. (Eds.), Handbook of Experimental Economics. Princeton University Press.

Erkal, N., Gangadharan, L., \& Nikiforakis, N. (2011). Relative earnings and giving in a real-effort experiment. American Economic Review, 101, 3330-3348.

Fehr, E., \& Schmidt, K.M. (1999). A theory of fairness, competition, and cooperation. Quarterly Journal of Economics, 114, 817-868.

Fehr, E., Kirchsteiger, G., \& Riedl, A. (1993). Does fairness prevent market clearing? An experimental investigation. Quarterly Journal of Economics, 108, 437-459.

Fischbacher, U. (2007). z-Tree: Zurich toolbox for ready-made economic experiments. Experimental Economics, 10, 171-178.

Freixas, X., Guesnerie, R., \& Tirole, J. (1985). Planning under incomplete information and the ratchet effect. Review of Economic Studies, 52, 173-191.

Gasper, J.T., \& Reeves, A. (2011). Make it rain? Retrospection and the attentive electorate in the context of natural disasters. American Journal of Political Science, 55, 340-355.

Goldin, C.D., \& Katz, L.F. (2009). The Race between Education and Technology. Harvard University Press.

Gómez-Miñambres, J. (2012). Motivation through goal setting. Journal of Economic Psychology, 33, 1223-1239.

Gould, R.V. (2002). The origins of status hierarchies: A formal theory and empirical test. American Journal of Sociology, 107, 1143-1178.

Healy, A.J., Malhotra, N., \& Mo, C.H. (2010). Irrelevant events affect voters' evaluations of government performance. Proceedings of the National Academy of Sciences, 107, 1280412809.

Heffetz, O. \& Frank, R. (2011). Preferences for Status: Evidence and Economic Implications. In Handbook of Social Economics, vol 1A. Bisin, A., Jackson, M., \& Benhabib, J. (eds.). Amsterdam: North-Holland. 
Hoekstra, M. (2009). The effect of attending the flagship state university on earnings: A discontinuity-based approach. Review of Economics and Statistics, 91, 717-724.

Holmström, B. (1999). Managerial incentive problems: A dynamic perspective. Review of Economic Studies, 66, 169-182.

Holt, C.A., \& Laury, S.K. (2002). Risk aversion and incentive effects. American Economic Review, 92, 1644-1655.

Hoxby, C.M. (2009). The changing selectivity of American colleges. Journal of Economic Perspectives, 23, 95-118.

Kahneman, D. (2011). Thinking: Fast and Slow. Farrar, Strauss and Giroux.

Konow, J. (2000). Fair shares: Accountability and cognitive dissonance in allocation decisions. American Economic Review, 90, 1072-1091.

Konow, J. (2003). Which is the fairest one of all? A positive analysis of justice theories. Journal of Economic Literature, 41, 1188-1239.

Krueger, A.B., \& Summers, L. (1988). Efficiency wages and the inter-industry wage structure. Econometrica, 56, 259-293.

Laffont, J.J., \& Martimort, D. (2002). The Theory of Incentives: The Principal-Agent Model. Princeton: Princeton University Press.

Malmendier, U., \& Nagel, S. (2011). Depression babies: Do macroeconomic experiences affect risk-taking? Quarterly Journal of Economics, 126, 373-416.

Malmendier, U., \& Nagel, S. (2016). Learning from inflation experiences. Quarterly Journal of Economics, 131, 53-87.

Manning, Alan (2011) Imperfect competition in the labor market. Handbook of Labor Economics, vol. 4, pp. 973-1041.

Markowitz, H. (1952). Portfolio selection. Journal of Finance, 7, 77-91.

Marshall, G.W., \& Mowen, J.C. (1993). An experimental investigation of the outcome bias in salesperson performance evaluations. Journal of Personal Selling and Sales Management, 13, 31-47.

Merton, R. K. (1968). The Matthew effect in science. Science, 159, 56-63.

Mobius, M.M., \& Rosenblat, T.S. (2006). Why beauty matters. American Economic Review, 96, 222-235.

Niederle, M., \& Vesterlund, L. (2007). Do women shy away from competition? Do men compete too much? Quarterly Journal of Economics, 122, 1067-1101.

Phelps, E.S. (1972). The statistical theory of racism and sexism. American Economic Review, 62, 4, 659-661.

Piketty, T. (2014). Capital in the Twenty-First Century. Trans. Arthur Goldhammer. Cambridge Massachusetts: The Belknap Press of Harvard University Press. 
Powdthavee, N., \& Riyanto, Y.E. (2015). Would you pay for transparently useless advice? A test of boundaries of beliefs in the folly of predictions. Review of Economics and Statistics, 97, 257-272.

Price, C.R. (2012). Gender, competition, and managerial decisions. Management Science, 58, 114122.

Reuben, E., Sapienza, P., \& Zingales, L. (2014). How stereotypes impair women's careers in science. Proceedings of the National Academy of Sciences, 111, 4403-4408.

Rey-Biel, P., Sheremeta, R.M., \& Uler, N. (2018). When income depends on performance and luck: The effects of culture and information on giving. In Research in Experimental Economics, ed. by Gunnthorsdottir, A., Norton, D., Caprar, D.V., forthcoming.

Ridgeway, C.L., \& Bourg, C. (2004). Gender as status: An expectation states theory approach. In The Psychology of Gender (2nd ed.), ed. by Eagly, A.H., Beall, A.E., and Sternberg, R.J. New York, NY: Guilford Press, pp. 217-241.

Rosenthal, R., \& Jacobson, L. (1968). Pygmalion in the Classroom. New York: Holt, Rinehart \& Winston.

Rubin, J., \& Sheremeta, R. (2016). Principal-agent settings with random shocks. Management Science, 62, 985-999.

Schneider, D.J. (2004). The Psychology of Stereotyping. New York, NY. Guilford Press.

Seltzer, N. (2009). GRE Practice Questions. Princeton Review.

Sorensen, A.B. (1996). The structural basis of social inequality. American Journal of Sociology, 101, 1333-1365.

Spence, M. (1973). Job market signaling. Quarterly Journal of Economics, 87, 355-374.

Stiglitz, J.E. (2012). The Price of Inequality: [how Today's Divided Society Endangers Our Future]. 1st Ed. New York: W.W. Norton \& Co.

Suetens, S., Galbo-Jørgensen, C.B., \& Tyran, J.R. (2016). Predicting lotto numbers: a natural experiment on the gambler's fallacy and the hot-hand fallacy. Journal of the European Economic Association, 14, 584-607.

Thaler, R.H. (2016). Behavioral economics: Past, present, and future. American Economic Review, 106, 1577-1600.

Wooldridge, J.M. (2001). Econometric Analysis of Cross Section and Panel Data. MIT Press.

Zellner, A. (1962). An efficient method of estimating seemingly unrelated regressions and tests for aggregation bias. Journal of the American Statistical Association, 57, 348-368. 
Figure 1: Overview of Experiment

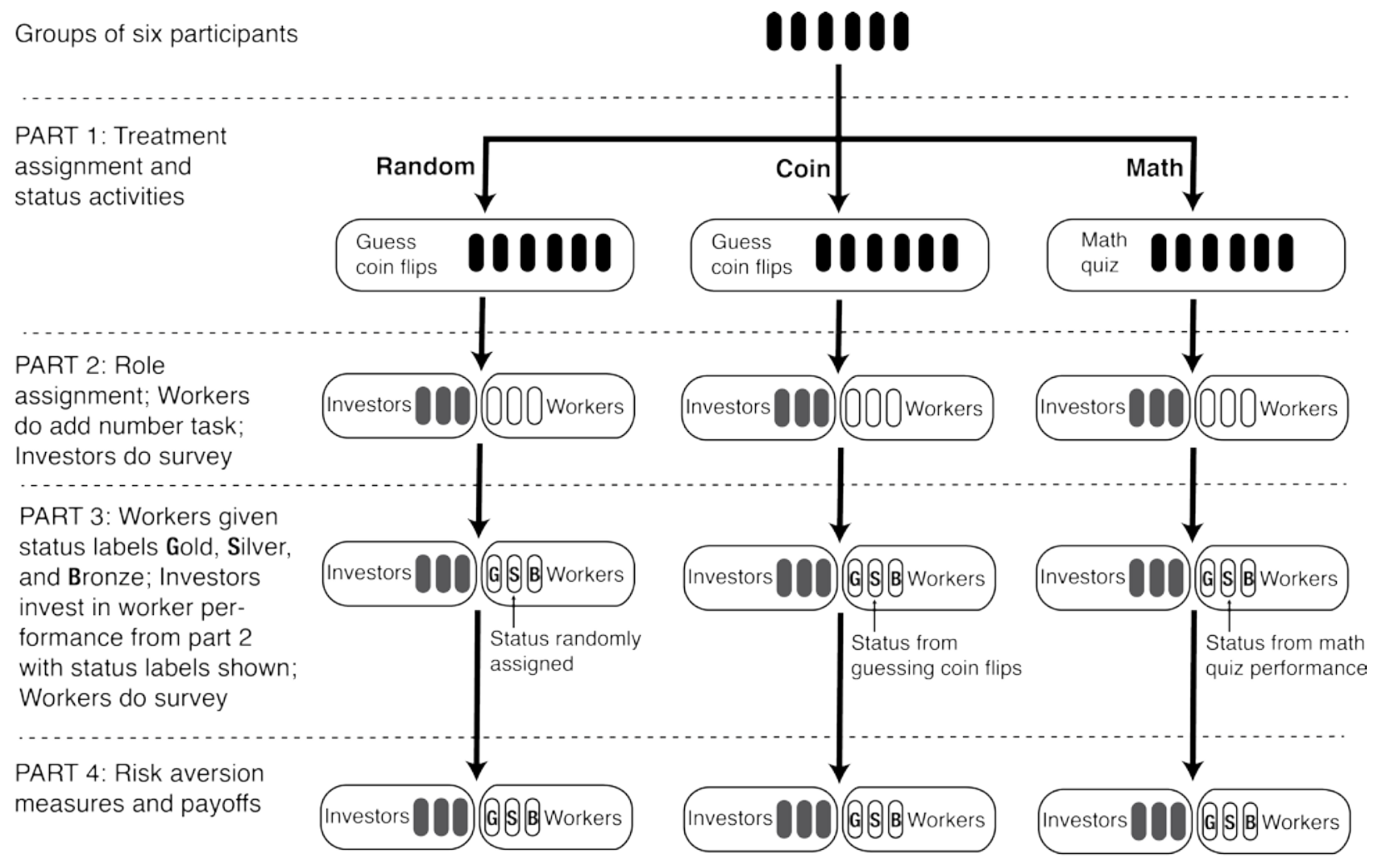


Table 1: Performance of Workers by Status and by Treatment

\begin{tabular}{lcccccc} 
& \multicolumn{3}{c}{ Part 1 (Coin flip/math quiz) } & \multicolumn{3}{c}{ Part 2 (Adding numbers) } \\
\cline { 2 - 7 } Treatment & Gold & Silver & Bronze & Gold & Silver & Bronze \\
\hline Random & 7.4 & 6.5 & 6.3 & 18.1 & 18.5 & 17.6 \\
& $(1.0)$ & $(0.8)$ & $(0.7)$ & $(2.2)$ & $(1.9)$ & $(2.6)$ \\
Coin & 9.1 & 7.4 & 5.5 & 16.1 & 16.7 & 17.3 \\
& $(0.2)$ & $(0.3)$ & $(0.3)$ & $(1.8)$ & $(1.7)$ & $(1.8)$ \\
Math & 6.8 & 5.0 & 2.7 & 15.3 & 17.9 & 10.9 \\
& $(0.5)$ & $(0.5)$ & $(0.4)$ & $(2.3)$ & $(1.4)$ & $(1.1)$ \\
\hline
\end{tabular}

The standard errors of the mean are in parentheses.

Table 2: Investments by Status and by Treatment

\begin{tabular}{lccccccccc} 
& \multicolumn{3}{c}{ Period 1 allocations } & \multicolumn{3}{c}{ Period 2 allocations } & \multicolumn{2}{c}{ Period 3 allocations } \\
\cline { 2 - 9 } Treatment & Gold & Silver & Bronze & Gold & Silver & Bronze & Gold & Silver & Bronze \\
\hline Random & 2.0 & 2.1 & 1.9 & 1.8 & 2.1 & 2.1 & 2.2 & 1.9 & 1.9 \\
& $(0.1)$ & $(0.1)$ & $(0.1)$ & $(0.2)$ & $(0.3)$ & $(0.2)$ & $(0.3)$ & $(0.2)$ & $(0.2)$ \\
Coin & 2.5 & 2.0 & 1.5 & 2.6 & 1.9 & 1.5 & 2.3 & 2.1 & 1.6 \\
& $(0.1)$ & $(0.1)$ & $(0.1)$ & $(0.2)$ & $(0.1)$ & $(0.2)$ & $(0.2)$ & $(0.1)$ & $(0.2)$ \\
Math & 3.1 & 1.8 & 1.1 & 3.2 & 1.8 & 1.0 & 3.1 & 1.8 & 1.1 \\
& $(0.2)$ & $(0.1)$ & $(0.1)$ & $(0.2)$ & $(0.1)$ & $(0.1)$ & $(0.2)$ & $(0.1)$ & $(0.1)$ \\
\hline
\end{tabular}

The standard errors of the mean are in parentheses.

Table 3: Predicting Worker Performance from History and Status

\begin{tabular}{|c|c|c|c|c|c|c|}
\hline & Random & Coin & Math & Random & Coin & Math \\
\hline & Periods 1-9 & Period 1-9 & Period 1-9 & Periods 2-9 & Periods 2-9 & Periods 2-9 \\
\hline & (1) & (2) & (3) & (4) & (5) & (6) \\
\hline \multirow[t]{2}{*}{ Gold } & 0.04 & -0.13 & $0.46^{*}$ & 0.20 & -0.08 & -0.09 \\
\hline & $(0.34)$ & $(0.26)$ & $(0.26)$ & (0.13) & $(0.10)$ & $(0.11)$ \\
\hline \multirow[t]{2}{*}{ Silver } & 0.08 & -0.04 & $0.71^{* * *}$ & 0.19 & -0.00 & 0.01 \\
\hline & $(0.32)$ & $(0.24)$ & (0.18) & (0.11) & (0.09) & (0.14) \\
\hline \multirow[t]{2}{*}{ Mean Prior Performance } & & & & $1.20^{* * *}$ & $1.32 * * *$ & $1.36^{* * *}$ \\
\hline & & & & $(0.12)$ & $(0.09)$ & (0.10) \\
\hline \multirow{2}{*}{ SD Prior Performance } & & & & 0.17 & $0.41^{* * *}$ & -0.26 \\
\hline & & & & $(0.31)$ & $(0.15)$ & $(0.20)$ \\
\hline \multirow[t]{2}{*}{ Last Period Performance } & & & & $-0.23 * * *$ & $-0.32 * * *$ & $-0.30^{* * *}$ \\
\hline & & & & $(0.07)$ & $(0.05)$ & $(0.05)$ \\
\hline \multirow[t]{2}{*}{ Constant } & $1.75^{* * *}$ & $1.71^{* * *}$ & $1.07^{* * *}$ & -0.02 & -0.12 & 0.25 \\
\hline & $(0.27)$ & $(0.19)$ & $(0.11)$ & $(0.20)$ & $(0.14)$ & $(0.15)$ \\
\hline Adjusted R2 & -0.01 & -0.00 & 0.08 & 0.53 & 0.62 & 0.55 \\
\hline$N$ & 216 & 324 & 324 & 192 & 288 & 288 \\
\hline
\end{tabular}

Notes: Stars indicate statistical significance $* p<0.1$; ** $p<0.05$; *** $p<0.01$. Standard errors allow for arbitrary correlation at the worker level. 


\section{Table 4: Investment, Status, and Performance History}

Panel A: Periods 2 through 10

\begin{tabular}{|c|c|c|c|c|c|c|}
\hline & \multicolumn{2}{|c|}{ Random } & \multicolumn{2}{|c|}{ Coin } & \multicolumn{2}{|c|}{ Math } \\
\hline & $\begin{array}{c}\text { Invested in } \\
\text { Gold }\end{array}$ & $\begin{array}{l}\text { Invested in } \\
\text { Silver }\end{array}$ & $\begin{array}{c}\text { Invested in } \\
\text { Gold }\end{array}$ & $\begin{array}{l}\text { Invested in } \\
\text { Silver }\end{array}$ & $\begin{array}{c}\text { Invested in } \\
\text { Gold }\end{array}$ & $\begin{array}{c}\text { Invested in } \\
\text { Silver }\end{array}$ \\
\hline & (1) & (2) & (3) & (4) & (5) & (6) \\
\hline \multirow{2}{*}{ Mean of Gold } & $1.50^{* * *}$ & -0.22 & $0.65 * * *$ & -0.28 & $0.98^{* * *}$ & $-0.58 * * *$ \\
\hline & $(0.31)$ & $(0.24)$ & $(0.18)$ & $(0.21)$ & $(0.18)$ & $(0.14)$ \\
\hline \multirow[t]{2}{*}{ Mean of Silver } & $-0.72 * *$ & $1.01^{* * *}$ & $-0.73 * * *$ & $1.21 * * *$ & -0.46 & $0.79 * * *$ \\
\hline & $(0.30)$ & $(0.22)$ & $(0.23)$ & $(0.25)$ & (0.38) & $(0.30)$ \\
\hline \multirow[t]{2}{*}{ Mean of Bronze } & $-0.60 * * *$ & $-0.58 * * *$ & $-0.39 * *$ & $-0.90 * * *$ & $-0.83 * * *$ & 0.04 \\
\hline & $(0.14)$ & $(0.18)$ & $(0.19)$ & $(0.19)$ & $(0.32)$ & $(0.25)$ \\
\hline \multirow[t]{2}{*}{ Last of Gold } & $0.26 * * *$ & $-0.20 * *$ & $0.29 * * *$ & $-0.11 *$ & $0.14^{* *}$ & $-0.10^{* * *}$ \\
\hline & (0.09) & (0.09) & $(0.07)$ & $(0.06)$ & $(0.06)$ & $(0.05)$ \\
\hline \multirow[t]{2}{*}{ Last of Silver } & -0.13 & $0.13^{*}$ & $-0.21^{* * *}$ & $0.38 * * *$ & $-0.18 * * *$ & $0.19 * * *$ \\
\hline & $(0.08)$ & (0.08) & $(0.07)$ & $(0.07)$ & $(0.07)$ & $(0.06)$ \\
\hline \multirow[t]{2}{*}{ Last of Bronze } & -0.04 & -0.04 & $-0.18 *$ & 0.03 & 0.15 & $-0.32 * * *$ \\
\hline & $(0.08)$ & (0.07) & (0.09) & $(0.12)$ & (0.13) & $(0.09)$ \\
\hline \multirow{2}{*}{ SD of Gold } & -0.31 & -0.02 & 0.52 & -0.48 & -0.59 & 0.41 \\
\hline & $(0.26)$ & $(0.26)$ & $(0.53)$ & $(0.50)$ & (0.58) & $(0.41)$ \\
\hline \multirow[t]{2}{*}{ SD of Silver } & -0.04 & -0.31 & -0.18 & -0.13 & 0.04 & $-0.28 *$ \\
\hline & $(0.26)$ & $(0.28)$ & $(0.28)$ & $(0.21)$ & $(0.26)$ & $(0.16)$ \\
\hline \multirow[t]{2}{*}{ SD of Bronze } & 0.14 & 0.18 & 0.30 & 0.22 & 0.79 & -0.23 \\
\hline & $(0.27)$ & $(0.28)$ & $(0.46)$ & $(0.40)$ & $(0.51)$ & $(0.30)$ \\
\hline \multirow[t]{2}{*}{ Constant } & $2.16^{* * *}$ & $1.84^{* * *}$ & $2.98 * * *$ & $1.64 * * *$ & $3.15 * * *$ & $1.49 * * *$ \\
\hline & $(0.21)$ & $(0.22)$ & $(0.37)$ & $(0.44)$ & $(0.35)$ & $(0.22)$ \\
\hline$\widehat{\alpha_{0}^{G}}$ & \multicolumn{2}{|c|}{$\begin{array}{l}{ }^{2.16^{* * * *}} \\
(0.21)\end{array}$} & \multicolumn{2}{|c|}{$\begin{array}{c}2.98^{* * * *} \\
(0.37)\end{array}$} & \multicolumn{2}{|c|}{$\begin{array}{c}3.15^{* * *} \\
(0.35)\end{array}$} \\
\hline$\widehat{\alpha_{0}^{S}}$ & \multicolumn{2}{|c|}{$\begin{array}{l}1.84 * * * \\
(0.22)\end{array}$} & \multicolumn{2}{|c|}{$\begin{array}{l}1.64^{* * *} \\
(0.44)\end{array}$} & \multicolumn{2}{|c|}{$\begin{array}{c}1.49 * * * \\
(0.22)\end{array}$} \\
\hline$\widehat{\alpha_{0}^{B}}$ & \multicolumn{2}{|c|}{$\begin{array}{l}2.00 * * * \\
(0.22)\end{array}$} & \multicolumn{2}{|c|}{$\begin{array}{l}1.38^{* * *} \\
(0.32)\end{array}$} & \multicolumn{2}{|c|}{$\begin{array}{c}1.36 * * * \\
(0.22)\end{array}$} \\
\hline$H_{0}: \widehat{\alpha_{0}^{G}}=\widehat{\alpha_{0}^{S}}=\widehat{\alpha_{0}^{B}}=2$ & \multicolumn{2}{|c|}{0.71} & \multicolumn{2}{|c|}{0.02} & \multicolumn{2}{|c|}{$<0.01$} \\
\hline$N$ & \multicolumn{2}{|c|}{216} & \multicolumn{2}{|c|}{324} & \multicolumn{2}{|c|}{324} \\
\hline
\end{tabular}

Panel B: Periods 6 through 10

\begin{tabular}{lcccc} 
& Random & Coin & Math & Math (High MAD) \\
\cline { 2 - 5 } & $(1)$ & $(2)$ & $(3)$ & $(4)$ \\
\hline$\widehat{\alpha_{0}^{G}}$ & $2.18^{* * *}$ & $2.39^{* * *}$ & $2.74^{* * *}$ & $2.91^{* * *}$ \\
$\widehat{\alpha_{0}^{S}}$ & $(0.39)$ & $(0.68)$ & $(0.47)$ & $(0.62)$ \\
$\widehat{\alpha_{0}^{B}}$ & $1.73^{* * *}$ & $2.05^{* * *}$ & $2.10^{* * *}$ & $1.80^{* * *}$ \\
& $(0.50)$ & $(0.56)$ & $(0.41)$ & $(0.52)$ \\
$H_{0}: \widehat{\alpha_{0}^{G}}=\widehat{\alpha_{0}^{S}}=\widehat{\alpha_{0}^{B}}=2$ & $2.10^{* * *}$ & $1.56^{* *}$ & $1.16^{* * *}$ & $1.29^{* * *}$ \\
\hline$N$ & $(0.32)$ & $(0.61)$ & $(0.34)$ & $(0.47)$ \\
& 0.86 & 0.76 & 0.05 & 0.24 \\
\hline
\end{tabular}

Notes: Stars indicate statistical significance $* p<0.1$; ${ }^{* *} p<0.05$; ${ }^{* * *} p<0.01$. Table reports estimates of the seemingly unrelated regression system in equations (2') and (3'). Standard errors are computed by bootstrap with resampling at the participant level. 
Table 5: Mediators of the Effect of Status on Investment

\begin{tabular}{lccc} 
& Random & Coin & Math \\
\cline { 2 - 4 } & $(1)$ & $(2)$ & $(3)$ \\
\hline Female & 0.24 & -0.91 & 0.13 \\
& $(0.71)$ & $(0.81)$ & $(0.77)$ \\
Caucasian & -0.15 & 0.54 & -0.05 \\
& $(0.77)$ & $(0.65)$ & $(0.89)$ \\
High GPA & -0.20 & -0.52 & 0.49 \\
& $(0.61)$ & $(0.67)$ & $(0.98)$ \\
Studies Business or Economics & 1.06 & 0.78 & -0.10 \\
& $(1.03)$ & $(0.72)$ & $(0.84)$ \\
Parental Income Over \$150K & -1.04 & 0.07 & 0.31 \\
& $(0.83)$ & $(0.67)$ & $(0.63)$ \\
Risk Averse (Incentive) & -0.09 & 0.45 & -0.11 \\
& $(0.63)$ & $(0.67)$ & $(0.87)$ \\
Risk Averse (Self-Evaluation) & 0.23 & -0.03 & -0.12 \\
& $(0.60)$ & $(0.77)$ & $(0.90)$ \\
Competitive & 0.52 & -0.08 & $1.16 *$ \\
& $(0.82)$ & $(0.83)$ & $(0.66)$ \\
Trusting & 0.77 & -0.26 & -1.04 \\
& $(0.80)$ & $(0.64)$ & $(0.94)$ \\
Constant & 1.34 & 0.72 & $1.45^{* *}$ \\
& $(0.87)$ & $(1.39)$ & $(0.75)$ \\
\hline$N$ & 216 & 324 & 324 \\
\hline
\end{tabular}

Notes: Stars indicate statistical significance ${ }^{*} p<0.1$; ${ }^{* *} p<0.05 ;{ }^{* * *} p<0.01$. Table reports the estimated differences in coefficients between equations (2') and (3') augmented to include dummy variables for the characteristics shown. Standard errors are computed by bootstrap with resampling at the participant level.

Table 6: Earnings by Treatment and Period

\begin{tabular}{|c|c|c|c|c|}
\hline & \multicolumn{2}{|c|}{ Mean Period Earnings } & \multicolumn{2}{|c|}{$\begin{array}{l}\text { Mean Period Share of } \\
\text { Maximum Earnings }\end{array}$} \\
\hline & (1) & (2) & (3) & (4) \\
\hline Coin & $\begin{array}{l}-0.25 \\
(0.67)\end{array}$ & $\begin{array}{c}0.05 \\
(0.67)\end{array}$ & $\begin{array}{l}-0.01 \\
(0.02)\end{array}$ & $\begin{array}{c}0.01 \\
(0.02)\end{array}$ \\
\hline Math & $\begin{array}{l}-1.74^{* *} \\
(0.78)\end{array}$ & $\begin{array}{l}-1.90^{* *} \\
(0.80)\end{array}$ & $\begin{array}{l}-0.08^{* * * *} \\
(0.02)\end{array}$ & $\begin{array}{l}-0.10^{* * * *} \\
(0.03)\end{array}$ \\
\hline Coin $\times$ Period $\geq 6$ & & $\begin{array}{l}-0.61 \\
(0.50)\end{array}$ & & $\begin{array}{l}-0.03 \\
(0.03)\end{array}$ \\
\hline Math $\times$ Period $\geq 6$ & & $\begin{array}{c}0.33 \\
(0.52)\end{array}$ & & $\begin{array}{c}0.04 \\
(0.03)\end{array}$ \\
\hline Period $\geq 6$ & & $\begin{array}{l}2.72^{* * * *} \\
(0.31)\end{array}$ & & $\begin{array}{l}0.08^{* * *} \\
(0.02)\end{array}$ \\
\hline Constant & $\begin{array}{l}11.53^{* * *} \\
(0.57)\end{array}$ & $\begin{array}{l}10.17^{* * * *} \\
(0.54)\end{array}$ & $\begin{array}{l}0.80^{* * *} \\
(0.01)\end{array}$ & $\begin{array}{l}0.76^{* * *} \\
(0.01)\end{array}$ \\
\hline $\begin{array}{l}\text { Adjusted R2 } \\
N\end{array}$ & $\begin{array}{c}0.03 \\
960\end{array}$ & $\begin{array}{c}0.12 \\
960\end{array}$ & $\begin{array}{r}0.03 \\
960\end{array}$ & $\begin{array}{c}0.08 \\
960\end{array}$ \\
\hline
\end{tabular}

Notes: Stars indicate statistical significance ${ }^{*} p<0.1 ; * * p<0.05$; ${ }^{* * *} p<0.01$. Standard errors are clustered at the participant level. 


\section{Appendix A - Instructions}

\section{GENERAL INSTRUCTIONS}

This is an experiment in the economics of decision-making. The instructions are simple. If you follow them carefully, you can make an appreciable amount of money.

There are 24 participants in todays' experiment. The experiment will proceed in 4 parts. Some parts contain decision problems that require you to make a series of choices that determine your total earnings. The currency used in all parts of the experiment is U.S. Dollars. You have already received a $\mathbf{\$ 7 . 0 0}$ participation fee. Your earnings from all parts of the experiment will be added to your participation fee. At the end of today's experiment, you will be paid in private and in cash.

Paper and pencil have been provided for you if you need them to do calculations.

It is very important that you remain silent and do not look at other people's work. If you have any questions, or need assistance of any kind, please raise your hand and an experimenter will come to you. If you talk, laugh, exclaim out loud, etc., you will be asked to leave and you will not be paid. We expect and appreciate your cooperation.

At this time we proceed to PART 1 of the experiment.

\section{PART 1}

[Random and Coin treatments] In PART 1 of the experiment you will be asked to predict the outcomes of a series of $\mathbf{1 5}$ coin tosses. The computer will randomly choose whether the outcome of each toss is heads or tails. There is a $\mathbf{5 0 \%}$ chance of heads and a $\mathbf{5 0 \%}$ chance of tails on each toss. You will earn $\mathbf{\$ 0 . 4 0}$ for each correct guess. There is no penalty for incorrect guesses. You may use the paper and pencil provided to work out your answers.

[Math treatment] In PART 1 of the experiment you will have 15 minutes to answer 10 quiz questions. The questions are from the mathematical section of the Graduate Record Examination. The questions are multiple-choice and have five potential answers 1 through 5. You will earn \$0.60 for each correct answer. There is no penalty for incorrect answers. You may use the paper and pencil provided to work out your answers.

The actual earnings for this part of the experiment will be determined at the end of the experiment, and will be independent of other parts of the experiment.

Please use the table below to record your decisions and then input them on your computer screen.

\section{PART 2}

In PART 2 of the experiment, the 24 participants in the room will be randomly divided into four groups of 6 people. The six people in each group will be divided in two roles: worker and investor. Each group will have 3 workers and 3 investors.

In this part, the workers will be in the "business" of solving a particular kind of math problem: adding together sets of five two-digit numbers. An example of the workers' task is to solve the problem: $34+55+72+41+63=$ . The correct answer to this problem is 265.

The worker's task will be divided into $\mathbf{1 0}$ periods. In each period, ten problems will appear on the screen for one minute. The worker will be paid $\mathbf{\$ 0 . 6 0}$ for each correct answer. There is no penalty for incorrect answers. You may use the paper and pencil provided to work out your answers. 
The actual earnings for this part of the experiment will be determined at the end of the experiment, and will be independent of other parts of the experiment.

While the workers are adding numbers, the investors will complete a demographic survey.

\section{PART 3}

[Random treatment] In PART 3 of the experiment, the computer will randomly assign a name to each worker in each group either as Gold, Silver, or Bronze.

[Coin treatment] In PART 3 of the experiment, the computer will rank each worker in each group as Gold, Silver, or Bronze depending on their relative scores from PART 1. Specifically, worker who had the most correct coin toss guesses in PART 1 will be called Gold, worker who was second will be called Silver, and worker who had the least correct coin toss guesses will be called Bronze.

[Coin treatment] In PART 3 of the experiment, the computer will rank each worker in each group as Gold, Silver, or Bronze depending on their relative scores from PART 1. Specifically, worker who had the most correct answers on math quiz in PART 1 will be called Gold, worker who was second will be called Silver, and worker who had the least correct answers on math quiz will be called Bronze.

In this part of the experiment, investors will make investment decisions, while workers will complete a demographic survey. Investors will make 10 investment decisions related to the performance of workers in their group in PART 2. For each decision to be made by an investor, the computer will randomly select one of the 10 periods from PART 2 for all three workers in the group. Once a period is selected, it can never be chosen again.

For each decision, investors will allocate $\mathbf{\$ 6}$ among the three workers in their group. The investor's allocations can vary in \$0.10 increments (for example \$1.20, \$1.80 and \$3.00), but they have to add up to $\$ 6$. The investor's earning for a given decision is calculated by the following formula: The investor's earning $=$ allocation to worker Gold $\times$ the number of problems solved correctly by worker Gold in PART $2+$ allocation to worker Silver $\times$ the number of problems solved correctly by worker Silver in PART $2+$ allocation to worker Bronze $\times$ the number of problems solved correctly by worker Bronze in PART 2.

For example, suppose that an investor allocates \$2 to worker Gold, \$3 to worker Silver, and $\$ 1$ to worker Bronze. Also, suppose that worker Gold solved 3 problems correctly in the randomly chosen period from PART 2, worker Silver solved 4 problems, and worker Bronze solved 0 problems. Then the investor will earn $\$ 2 \times 3=\$ 6$ from their allocation to worker Gold, $\$ 3 \times 4=\$ 12$ from their allocation to worker Silver, and $\$ 1 \times 0=\$ 0$ from their allocation to worker Bronze. Their total earnings are $\$ 6+\$ 12+\$ 0=\$ 18$.

After each investment decision has been made, the computer will randomly choose one of the 10 periods from PART 2. Then the computer will display the number of problems solved correctly for each worker in the selected period. The computer will also calculate the investor's earnings based on the investor's allocation to each worker and their corresponding performance in that period.

The actual earnings for this part of the experiment will be determined at the end of the experiment, and will be independent of other parts of the experiment. At the end of the experiment the computer will randomly select one of the 10 investment decisions for actual payment.

Please use the table below to record your decisions and then input them on your computer screen.

PART 4 
In PART 4 of the experiment, you will be asked to make choices in 15 decision problems. How much money you receive will depend partly on chance and partly on the choices you make.

On your computer screen you will see a table with 15 lines (as shown below). In each line you will state whether you prefer Option A or Option B. Option A always offers a 50\% chance to get $\$ 10$ and a $50 \%$ chance to get $\$ 0$, while Option B always offers a certain amount for sure (between $\$ 0.50$ and $\$ 7.50$, depending on the line). You should think of each line as a separate decision you need to make. However, only one line will be the 'line that counts' and will be paid out.

\begin{tabular}{|c|c|c|c|c|}
\hline Decision & \multicolumn{2}{|c|}{ Option A } & Option B & Choose \\
\hline 1 & $\$ 10.00$ with $50 \%$ chance & $\$ 0.00$ with $50 \%$ chance & $\$ 0.50$ for sure & \\
\hline 2 & $\$ 10.00$ with $50 \%$ chance & $\$ 0.00$ with $50 \%$ chance & $\$ 1.00$ for sure & \\
\hline 3 & $\$ 10.00$ with $50 \%$ chance & $\$ 0.00$ with $50 \%$ chance & $\$ 1.50$ for sure & \\
\hline 4 & $\$ 10.00$ with $50 \%$ chance & $\$ 0.00$ with $50 \%$ chance & $\$ 2.00$ for sure & \\
\hline 5 & $\$ 10.00$ with $50 \%$ chance & $\$ 0.00$ with $50 \%$ chance & $\$ 2.50$ for sure & \\
\hline 6 & $\$ 10.00$ with $50 \%$ chance & $\$ 0.00$ with $50 \%$ chance & $\$ 3.00$ for sure & \\
\hline 7 & $\$ 10.00$ with $50 \%$ chance & $\$ 0.00$ with $50 \%$ chance & $\$ 3.50$ for sure & \\
\hline 8 & $\$ 10.00$ with $50 \%$ chance & $\$ 0.00$ with $50 \%$ chance & $\$ 4.00$ for sure & \\
\hline 9 & $\$ 10.00$ with $50 \%$ chance & $\$ 0.00$ with $50 \%$ chance & $\$ 4.50$ for sure & \\
\hline 10 & $\$ 10.00$ with $50 \%$ chance & $\$ 0.00$ with $50 \%$ chance & $\$ 5.00$ for sure & \\
\hline 11 & $\$ 10.00$ with $50 \%$ chance & $\$ 0.00$ with $50 \%$ chance & $\$ 5.50$ for sure & \\
\hline 12 & $\$ 10.00$ with $50 \%$ chance & $\$ 0.00$ with $50 \%$ chance & $\$ 6.00$ for sure & \\
\hline 13 & $\$ 10.00$ with $50 \%$ chance & $\$ 0.00$ with $50 \%$ chance & $\$ 6.50$ for sure & \\
\hline 14 & $\$ 10.00$ with $50 \%$ chance & $\$ 0.00$ with $50 \%$ chance & $\$ 7.00$ for sure & \\
\hline 15 & $\$ 10.00$ with $50 \%$ chance & $\$ 0.00$ with $50 \%$ chance & $\$ 7.50$ for sure & \\
\hline
\end{tabular}

At the end of the experiment the computer will randomly draw one line for payment. Your earnings for the selected line depend on which option you chose: If you chose A in that line, then the computer will randomly choose either $\$ 10$ or $\$ 0$ with equal chances as your payment. If you chose B in that line, then you will receive for sure the exact amount that is specified by Option B in that line.

\section{EARNINGS}

Participation fee

PART 1

PART 2

PART 3

PART 4

You total earnings 


\section{Appendix B - Supplementary Tables}

\section{Table B1: Investment, Status, and Performance History with Additional Decision Variables}

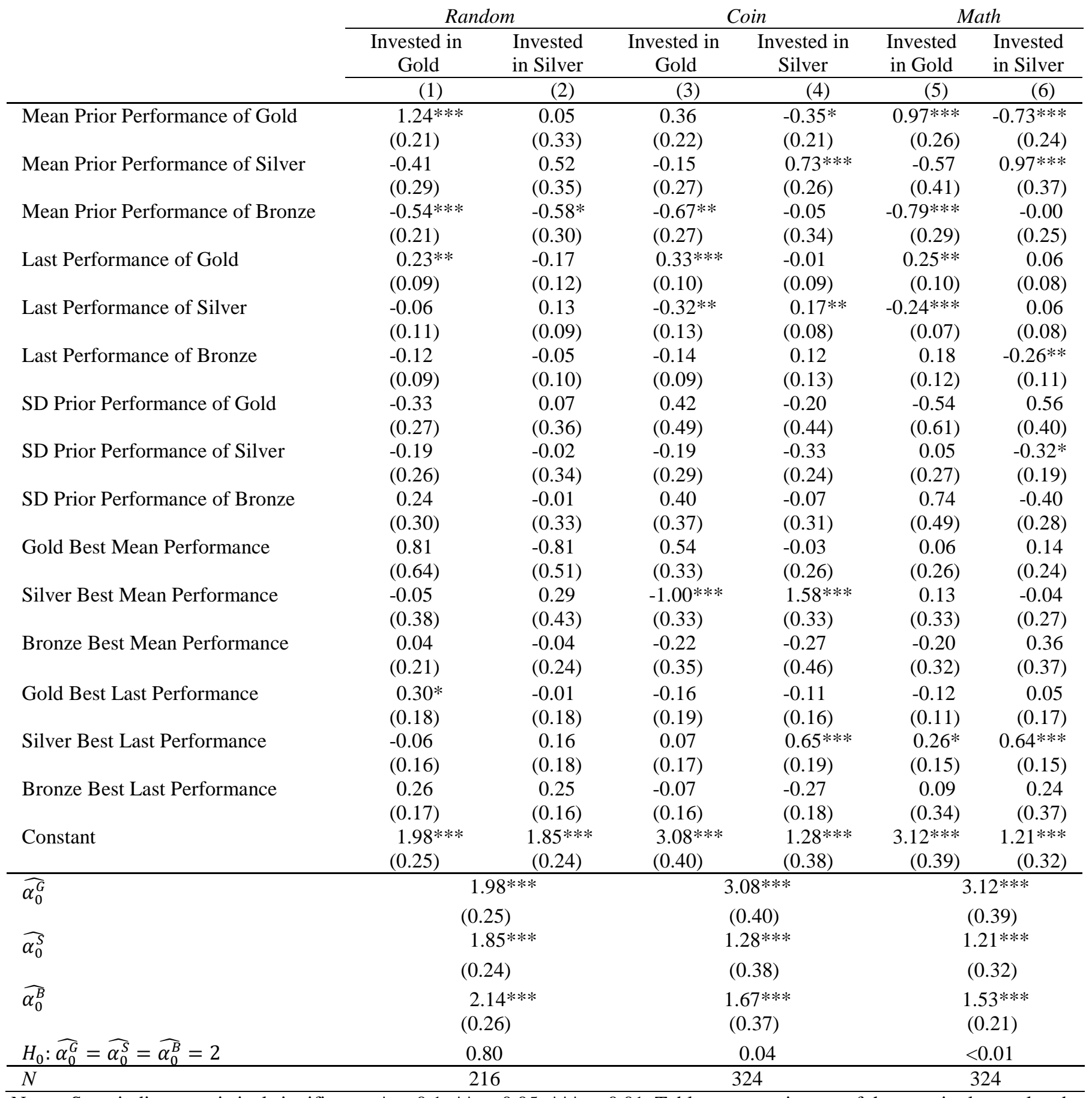

Notes: Stars indicate statistical significance $* p<0.1 ; * * p<0.05 ; * * * p<0.01$. Table report estimates of the seemingly unrelated regression system in equations (2') and (3'). Standard errors are computed by bootstrap with resampling at the participant level 
Table B2: Investment, Status, and Performance History with Group Clustered Errors

\begin{tabular}{|c|c|c|c|c|c|c|}
\hline & \multicolumn{4}{|c|}{ Panel A: Periods 2 through 10} & \multirow{2}{*}{\multicolumn{2}{|c|}{ Math }} \\
\hline & \multicolumn{2}{|c|}{ Random } & \multicolumn{2}{|c|}{ Coin } & & \\
\hline & $\begin{array}{l}\text { Invested in } \\
\text { Gold }\end{array}$ & $\begin{array}{l}\text { Invested in } \\
\text { Silver }\end{array}$ & $\begin{array}{l}\text { Invested in } \\
\text { Gold }\end{array}$ & $\begin{array}{l}\text { Invested in } \\
\text { Silver }\end{array}$ & $\begin{array}{l}\text { Invested } \\
\text { in Gold }\end{array}$ & $\begin{array}{l}\text { Invested } \\
\text { in Silver }\end{array}$ \\
\hline & (1) & (2) & (3) & (4) & (5) & (6) \\
\hline \multirow[t]{2}{*}{ Mean of Gold } & $1.50^{* * *}$ & -0.22 & $0.65^{* *}$ & -0.28 & $0.98^{* * *}$ & $-0.58^{* *}$ \\
\hline & $(0.31)$ & $(0.52)$ & $(0.28)$ & $(0.31)$ & $(0.27)$ & $(0.23)$ \\
\hline \multirow[t]{2}{*}{ Mean of Silver } & $-0.72 * *$ & $1.01^{* *}$ & -0.73 & $1.21 * *$ & -0.46 & $0.79 *$ \\
\hline & $(0.36)$ & $(0.48)$ & $(0.46)$ & $(0.52)$ & $(0.52)$ & (0.43) \\
\hline \multirow[t]{2}{*}{ Mean of Bronze } & $-0.60 * *$ & $-0.58 * *$ & $-0.39 *$ & $-0.90 * * *$ & $-0.83^{*}$ & 0.04 \\
\hline & $(0.25)$ & $(0.26)$ & $(0.22)$ & $(0.28)$ & $(0.46)$ & $(0.37)$ \\
\hline \multirow[t]{2}{*}{ Last of Gold } & $0.26^{* * *}$ & $-0.20 * *$ & $0.29 * * *$ & -0.11 & $0.14 * *$ & -0.10 \\
\hline & $(0.09)$ & $(0.09)$ & $(0.09)$ & $(0.09)$ & $(0.07)$ & $(0.07)$ \\
\hline \multirow[t]{2}{*}{ Last of Silver } & -0.13 & 0.13 & $-0.21 *$ & $0.38^{* * *}$ & $-0.18 * *$ & $0.19 * *$ \\
\hline & $(0.09)$ & $(0.09)$ & $(0.11)$ & $(0.07)$ & $(0.08)$ & $(0.08)$ \\
\hline \multirow[t]{2}{*}{ Last of Bronze } & -0.04 & -0.04 & $-0.18^{* *}$ & 0.03 & 0.15 & $-0.32 * *$ \\
\hline & (0.09) & $(0.07)$ & $(0.07)$ & (0.13) & $(0.19)$ & (0.15) \\
\hline \multirow[t]{2}{*}{ SD of Gold } & -0.31 & -0.02 & 0.52 & -0.48 & -0.59 & 0.41 \\
\hline & $(0.50)$ & (0.53) & $(0.77)$ & $(0.75)$ & $(0.58)$ & $(0.45)$ \\
\hline \multirow[t]{2}{*}{ SD of Silver } & -0.04 & -0.31 & -0.18 & -0.13 & 0.04 & -0.28 \\
\hline & (0.38) & $(0.47)$ & $(0.45)$ & $(0.40)$ & $(0.41)$ & $(0.23)$ \\
\hline \multirow[t]{2}{*}{ SD of Bronze } & 0.14 & 0.18 & 0.30 & 0.22 & 0.79 & -0.23 \\
\hline & (0.49) & $(0.52)$ & $(0.67)$ & $(0.54)$ & $(0.51)$ & $(0.34)$ \\
\hline \multirow{2}{*}{ Constant } & $2.16^{* * *}$ & $1.84^{* * *}$ & $2.98^{* * *}$ & $1.64^{* *}$ & $3.15^{* * *}$ & $1.49 * * *$ \\
\hline & $(0.36)$ & $(0.57)$ & $(0.63)$ & $(0.77)$ & $(0.41)$ & $(0.31)$ \\
\hline \multirow[t]{2}{*}{$\widehat{\alpha_{0}^{G}}$} & \multirow{2}{*}{\multicolumn{2}{|c|}{$\begin{array}{l}2.16^{* * *} \\
(0.36)\end{array}$}} & \multirow{2}{*}{\multicolumn{2}{|c|}{$\begin{array}{l}2.98 * * * \\
(0.63)\end{array}$}} & \multirow{2}{*}{\multicolumn{2}{|c|}{$\begin{array}{l}3.15^{* * * *} \\
(0.41)\end{array}$}} \\
\hline & & & & & & \\
\hline$\widehat{\alpha_{0}^{S}}$ & \multicolumn{2}{|c|}{$\begin{array}{l}1.84 * * * \\
(0.57)\end{array}$} & \multicolumn{2}{|c|}{$\begin{array}{l}1.64^{* * * *} \\
(0.77)\end{array}$} & \multicolumn{2}{|c|}{$\begin{array}{l}1.49 * * * \\
(0.31)\end{array}$} \\
\hline$\widehat{\alpha_{0}^{B}}$ & \multicolumn{2}{|c|}{$\begin{array}{l}2.00 * * * \\
(0.49)\end{array}$} & \multicolumn{2}{|c|}{$\begin{array}{l}1.38^{* * *} \\
(0.52)\end{array}$} & \multicolumn{2}{|c|}{$\begin{array}{l}1.36^{* * * *} \\
(0.20)\end{array}$} \\
\hline$H_{0}: \widehat{\alpha_{0}^{G}}=\widehat{\alpha_{0}^{S}}=\widehat{\alpha_{0}^{B}}=2$ & \multicolumn{2}{|c|}{0.94} & \multicolumn{2}{|c|}{0.17} & \multicolumn{2}{|c|}{$<0.01$} \\
\hline$N$ & \multicolumn{2}{|c|}{216} & & & & 24 \\
\hline
\end{tabular}

Notes: Stars indicate statistical significance $* p<0.1$; ** $p<0.05$; *** $p<0.01$. Table report estimates of the seemingly unrelated regression system in equations (2') and (3'). Standard errors are computed by bootstrap with resampling at the group level. 